\title{
PERFORMANCE E EXPERIÊNCIA NAS NARRAIIVAS ORAIS DA FRONTEIRA ENTRE ARGENTINA, BRASIL E URUGUAI
}

\author{
Luciana Hartmann \\ Universidade Federal do Rio de Janeiro - Brasil
}

Resumo: Na fronteira entre Argentina, Brasil e Uruguai as narrativas orais transgridem limites políticos e, ao circularem entre as vizinhas regiões, vão revelando identidades, tradições, sentimentos. Esta transmissão de valores e práticas que se dá através da narração de histórias é parte fundamental da "cultura da fronteira", existente entre os três países enfocados. Neste artigo abordo um aspecto específico desta cultura, aquele que diz respeito às performances dos contadores de causos/cuentos e sua importância na organização e transmissão da experiência de viver na fronteira. Inicialmente faço um levantamento teórico da relação entre experiência, performance e narrativa. Na seqüência, demonstro, através de duas narrativas - um "causo" cômico e uma história pessoal - como os conceitos de "performance como espetáculo" e "performance como desempenho", depreendidos da análise dos dados empíricos, auxiliaram na compreensão das diferentes formas de engajamento de contadores $e$ ouvintes nos eventos narrativos da região.

Palavras-chave: experiência, fronteira, narrativas orais, performance.

Abstract: In the frontier among Argentina, Brazil and Uruguay oral narratives transpose political limits. On circulating in this region, narratives reveal identities, traditions and even feelings. In these countries the practice of storytelling is a central aspect of a "culture of frontier", it is fundamental for transmitting values and knowledge. In this paper I present an specific aspect of this culture: the story-tellers performances and its importance on the organization and transmission of the experience of living in the frontier. Firstly, it is done a theoretical approach about the relationship among experience, performance and narrative definitions. Then, presenting two narratives - one a comic story, and the other a personal life narrative - I explain how concepts of "performance as an exhibition" and "performance as skill" can be useful to understand the different forms storytellers act in narrative events.

Keywords: borders, experience, oral narratives, performance. 
Para muitos pesquisadores, o trabalho com narrativas está sempre, e inevitavelmente, relacionado à problemática da experiência. Segundo essa perspectiva, da qual compartilho, uma das principais maneiras que o ser humano teria de manifestar, comunicar e até mesmo compreender a experiência seria colocá-la sob a forma narrativa. Essa "forma”, entretanto, envolve tanto a colocação de palavras em estruturas inteligíveis de significado quanto a organização de uma série de códigos e dispositivos culturais que permitem que a narrativa seja compreendida. Estes últimos serão mais ricos e informarão mais a respeito da cultura em questão à medida que estiverem sendo observados num "evento" onde os significados são negociados e atualizados no ato mesmo de sua produção. Em outras palavras, ao contrário do que ocorre nas narrativas escritas, nas performances narrativas o tempo e o espaço do contador encontram-se com o tempo e o espaço da audiência, propiciando uma interação, um diálogo e uma troca de experiências que estão, neste "aqui e agora" compartilhado, mostrando a própria cultura em emergência (Bauman, 1977).

Antes de considerar a questão da performance ${ }^{2}$ propriamente dita, será interessante fazer algumas considerações sobre a noção de experiência. De acordo com Bruner (1986, p. 4), a experiência não se dá apenas através de dados, da cognição ou da razão, mas também envolve sentimentos e expectativas. Partindo da obra de Dilthey, para quem a realidade só existe através da consciência dada pela experiência interior, Bruner vai argumentar que a experiência vivida, como pensamento e desejo, como palavra e imagem, é a primeira realidade. Nesse sentido, toda experiência é exclusivamente pessoal, individual, única e nunca poderá ser totalmente partilhada. A chave para tentar transcender essa limitação seria interpretar as expressões da experiência. São estas expressões (performances, narrativas, textos...) que darão forma e significado às experiências, no âmbito da intersubjetividade. E aqui chegamos ao círculo

\footnotetext{
1 Um dos conceitos-chave na obra de Bauman (1977), o evento - subdividido em "evento narrativo" (a situação discursiva da sua narração) e “evento narrado” (as palavras e ações que nele são relatadas) é um dos princípios organizadores da etnografia da performance. O termo é usado para designar um segmento limitado e culturalmente definido do fluxo de comportamento e da experiência, que constitui um contexto significativo para a ação.

$2 \mathrm{O}$ conceito de performance aqui utilizado relaciona-se às práticas estéticas que envolvem padrões de comportamento, maneiras de falar, maneiras de se comportar corporalmente - cujas repetições situam os atores sociais no tempo e no espaço, estruturando identidades individuais e de grupo (Kapchan, 1995).
}

Horizontes Antropológicos, Porto Alegre, ano 11, n. 24, p. 125-153, jul./dez. 2005 
hermenêutico de Dilthey (apud Bruner, 1986, p. 6, tradução minha), já que “a experiência estrutura as expressões e as expressões estruturam a experiência”.

É na relação, na tensão e nas inevitáveis lacunas entre realidade (o que está realmente lá, o que pode estar), experiência (como a realidade se apresenta à consciência) e expressões (como a experiência individual é enquadrada e articulada) que está o foco da antropologia da experiência - à qual este trabalho se filia - e as possíveis chaves para a interpretação dos seus significados. As narrativas surgirão, na perspectiva de Bruner, não enquanto textos fixos, mas como uma forma de expressão inserida no fluxo da ação social. Olhando, assim, para as narrativas como parte de um contexto que é também histórico, nos deparamos com a questão da dimensão temporal da experiência:

Criamos unidades de experiência e significado da continuidade da vida. Cada narração é uma imposição arbitrária de significado no fluxo na memória, no qual iluminamos algumas causas e obscurecemos outras; isto é, toda narração é interpretativa. (Bruner, 1986, p. 7, tradução minha).

Enfim, o que Bruner está defendendo é que o estudo da cultura inicie pelas expressões, já que estas representam articulações e formulações da experiência em unidades de análise estabelecidas pelos seus próprios membros. É importante considerar, entretanto, que os participantes de uma performance, ritual ou evento narrativo não necessariamente partilham uma experiência ou significado comuns, o que eles estão partilhando é somente a sua participação neste ou naquele evento. E neste processo de "interpretação das culturas", ambicionado pelos antropólogos, concorrem ainda, segundo Bruner (1985, p. 10), dois níveis interpretativos: o dos membros da cultura estudada, que interpretam suas próprias experiências em formas expressivas, e o dos antropólogos, que interpretam essas expressões para seus pares acadêmicos (produzindo eles próprios outras expressões).

Das várias estratégias utilizadas pelos antropólogos na busca do significado, vou me deter naquelas que, procurando uma aproximação cada vez mais intensa com o "ponto de vista nativo" (Geertz, 1997), encontram nas próprias narrativas e performances destes uma via de acesso privilegiada às interpretações que os membros da cultura estudada fazem de si mesmos (Bauman; Briggs, 1990; Briggs, 1985; Hartmann, 2002; Langdon, 1999; Maluf, 1999; Rosaldo, 1986). E mais, assumem a etnografia como uma forma narrativa, que é, dessa maneira, também modelada e sujeita aos humores do autor e às exigências de 
seus pares (Bruner, 1986). Estamos aqui no âmbito do relativismo: cada performance e cada etnografia são relativas a um determinado contexto cultural e seu significado só pode ser compreendido nesse contexto. Mas o que faz com que o contexto possa ser compreendido? Justamente aquilo que nos une enquanto seres culturais, segundo Lévi-Strauss (1967), nossa capacidade de nos comunicarmos através de símbolos, pela linguagem. A grande questão, no entanto, é que não estamos tratando apenas da linguagem falada ou escrita, de códigos gramaticais, mas de algo muito mais amplo, daquela linguagem que se desenvolve através de gestos, sons, da relação com o espaço físico e do contato como o outro, aquilo que chamamos de "performance". Esta também possui seus códigos, mas possibilita que tanto o conhecimento produzido pela cultura quanto a reflexão sobre este envolvam seus participantes de uma forma "multisensorial” (Langdon, 1999, p. 29).

Em The Anthropology of Experience, Kapferer (1986) também vai salientar a importância da performance na análise do significado e da experiência proporcionada pelo ritual e por outros modos de ação simbólica. Para ele (Kapferer, 1986, p. 191), as performances formam uma unidade entre texto e ação, constituindo e ordenando a experiência tanto quanto servindo para a reflexão e comunicação desta. No mesmo livro, Geertz (1986, p. 380) comenta que as experiências, ao mesmo tempo em que são construídas nos contos, festas, cerâmicas, ritos, dramas, imagens, memórias, etnografias e maquinarias alegóricas, também lhes constroem.

Ao realizar uma revisão das teorias sobre a natureza da performance, Sullivan (1986), encontra reivindicações comuns: 1) há um “procedimento reconhecido” que ordena as ações da performance; 2) há um senso de representação coletiva que é proposital; 3) há uma "consciência” comum de que os atos performatizados são diferentes dos eventos ordinários, do cotidiano (Sullivan, 1986, p. 5). Para ele, todas essas teorias são tentativas de delinear, analisar ou interpretar as "qualidades do conhecimento" que inspiram a ação humana durante a performance cultural. ${ }^{3} \mathrm{Na}$ performance as expressões simbólicas concorrem para uma "unidade dos sentidos" (sinestesia) que habilitaria a cultura a

${ }^{3}$ O autor está trabalhando com o conceito de Singer (1972) de "performance cultural” - uma forma de expressão artística que obedece a uma programação prévia da comunidade, com local próprio para sua ocorrência, horário definido para início e fim das atividades, delimitação entre performers e público, etc.

Horizontes Antropológicos, Porto Alegre, ano 11, n. 24, p. 125-153, jul./dez. 2005 
“entreter a si própria com a idéia da unidade de significados” (Sullivan, 1986, p. 6, tradução minha). Fundamentalmente, no entanto, a performance para este autor é uma forma de hermenêutica, pois tem como principal constituinte de sua ação a reflexividade. Mas, antes de refletir, ela está relacionada à própria apreensão da experiência: "[...] o ato de compreender é performativo por natureza” (Sullivan, 1986, p. 30, tradução minha), o que nos faz voltar ao círculo hermenêutico, pois, segundo esta perspectiva, a performance tanto dá forma ${ }^{4}$ quanto é formada pela experiência.

Já Zumthor (2000, p. 37) propõe uma inversão da perspectiva etnológica, pois, segundo ele, enquanto a etnologia vai se referir aos conteúdos da performance ou às formas de transmissão destes, ele os toma em relação aos "hábitos receptivos". Mas as características que o autor encontra para definir a performance estão totalmente relacionadas às pesquisas etnológicas/antropológica. São elas: 1) a performance realiza, concretiza, faz passar algo que eu reconheço, da virtualidade à atualidade; 2 ) a performance situa-se num contexto ao mesmo tempo cultural e situacional: nesse contexto ela aparece como uma "emergência", ${ }^{5}$ 3.) performance é uma conduta na qual o sujeito assume, aberta e funcionalmente, a responsabilidade, e é um comportamento que pode ser repetitivo sem ser redundante (semelhante ao que Schechner (1988) define como "comportamento restaurado"6); 4) a performance modifica o conhecimento. Ela não é simplesmente um meio de comunicação: comunicando ela os marca. Em outro momento de seu texto, Zumthor traz à tona o que, creio, seja o grande mérito de sua abordagem da performance: relacioná-la à prática da linguagem poética, ligando esta ao corpo.

[...] o poético (diferente de outros discursos) tem de profundo, fundamental necessidade, para ser percebido em sua qualidade e para gerar seus efeitos, da presença ativa de um corpo: de um sujeito em sua plenitude psicofisiológica

\footnotetext{
4 Interessante perceber na etimologia da palavra, par former, de origem francesa, sua primeira acepção já ligada ao “dar forma” (ao conhecimento, à experiência, à imaginação, etc.).

5 Vamos encontrar a mesma questão mais desenvolvida em Bauman (1977).

6 A teoria do “comportamento restaurado" considera aquelas ações corporais que podem ser repetidas (atualizadas, restauradas) da mesma maneira pelos sujeitos “em performance”. A diferença é que estes comportamentos, para Schechner (1988; 1992), não seriam marcas de identificação cultural/social cotidianos, mas ações simbólicas, de cunho estético, realizadas especificamente em processos rituais ou em dramas estéticos.
}

Horizontes Antropológicos, Porto Alegre, ano 11, n. 24, p. 125-153, jul./dez. 2005 
particular, sua maneira própria de existir no espaço e no tempo e que ouve, vê, respira, abre-se aos perfumes, ao tato das coisas. Que um texto seja reconhecido por poético (literário) ou não, depende do sentimento que nosso corpo tem. Necessidade para produzir seus efeitos; isto é, para nos dar prazer. (Zumthor, 2000, p. 41).

Como se percebe, tanto Sullivan quanto Zumthor, direta ou indiretamente, inspiram-se nas mesmas fontes e podemos verificar fatores comuns nas suas caracterizações de performance, sendo que ambas as perspectivas poderiam ser canalizadas na clássica definição de Bauman (1977, p. 11), que compreende a performance como um modo de comunicação verbal que consiste na tomada de responsabilidade, de um performer, para uma audiência, através da manifestação de sua competência comunicativa. Essa competência apóia-se no conhecimento e na habilidade que ele possua para falar nas vias socialmente apropriadas. Do ponto de vista da audiência, o ato de expressão do performer é sujeito à avaliação, de acordo com sua eficiência. Quanto mais hábil, mais intensificará a experiência, através do prazer proporcionado pelas qualidades intrínsecas ao ato de expressão. No entanto, Bauman, ao manter sua análise no âmbito da comunicação verbal, não toca em algo a que os autores acima citados, ao contrário, dedicam grande atenção: a questão do envolvimento integral do corpo e de suas sensações em todo e qualquer ato de performance.

Uma outra importante abordagem dos estudos da performance, proposta em artigo de Bauman e Briggs (1990), segue a mesma linha de Sullivan e Zumthor, adotando, porém, uma perspectiva mais crítica ao repensar a forma com que o contexto estava sendo trabalhado nas análises de performances narrativas. Assumindo que um texto não pode ser compreendido sem seu relativo contexto, os autores propõem, no entanto, que se considere este não mais em termos “normativos, convencionais e institucionais” (Bauman; Briggs, 1990, p. 67) mas como "um ativo processo de negociação no qual os participantes examinam reflexivamente o discurso na forma como ele está emergindo [...]" (Bauman; Briggs, 1990, p. 69, tradução minha). Este processo, no qual o próprio etnógrafo deve também se incluir, Bauman e Briggs chamam de contextualização: a análise da emergência de textos em contextos. Também para esses autores a performance é um modo de comunicação altamente reflexivo, que realiza a “função poética” (Jakobson apud Bauman; Briggs, 1990, p. 73).

Em artigo de 1999, Langdon traça um histórico dos estudos de literatura oral na antropologia, desde o seu início através da análise de mitos, onde os textos fixos eram utilizados no sentido de fornecerem informações sobre uma 
dada cultura, sua linguagem ou sua psicologia, até as abordagens contemporâneas, que analisam o texto oral segundo uma perspectiva dramática, performática, onde suas qualidades estéticas e emergentes serão especialmente valorizadas. A autora vai trabalhar não apenas com a questão da "fixação da narrativa", como consta do título do artigo, mas também com a fixação da experiência de interação social (abordada por Geertz), especialmente aquela marcada pelos eventos narrativos, num texto escrito. Acompanhando a utilização do conceito de performance na antropologia, instaurado pelos “pós-modernos”, a partir dos últimos vinte anos, ela considera que esta se relaciona ao imprevisto (ou improvisado), à heterogeneidade, à polifonia de vozes, às relações de poder, à subjetividade e às transformações contínuas, pontuando também que o conceito dá conta de análises de fenômenos sociais tanto em sociedades complexas quanto em sociedades ágrafas. Para a autora, a noção de performance envolve dois paradigmas antropológicos: ${ }^{7}$

a) a vida social como dramatúrgica (Goffman, 1983) ou como drama social (Geertz, 1989; Turner, 1981, 1992): para estes últimos, ao contrário de Goffman, o enfoque não está na regra, mas na práxis e na interação dos atores sociais: aqui a vida é vista como uma seqüência de dramas sociais, resultados de uma tensão contínua entre harmonia e conflito. Langdon salienta o interesse posterior de Turner nas "performances culturais", a partir dos trabalhos desenvolvidos por Singer (1972) e Schechner (1992). Nessa perspectiva, os momentos de performance aparecem como momentos de reflexividade, que podem levar à transformação - a narrativa é vista como um evento social, que envolve experiência, subjetividade, expressões artísticas. A ênfase dessa abordagem está na relação culturaperformance-sociedade;

b) a performance como evento (Bauman, 1977, 1986; Bauman; Sherzer, 1975): em sua "perspectiva performática”, Bauman vai preocupar-se com a própria criação/construção da performance nas diferentes culturas e

\footnotetext{
Schieffelin $(1996,1998)$ também vem trabalhando no mesmo sentido, dividindo em duas as principais correntes de uso do termo "performance" em antropologia. À diferença de Langdon, no entanto, este autor alia à discussão da performance na vida cotidiana, de Goffman, não os estudos de Turner e Schechner (aos quais meu trabalho se filia), mas à "teoria da prática”, de Bourdieu (na qual as performances participam do habitus como "improvisações reguladas").
}

Horizontes Antropológicos, Porto Alegre, ano 11, n. 24, p. 125-153, jul./dez. 2005 
nos diferentes gêneros. A performance, como um ato de comunicação, distingue-se dos outros atos de fala pela sua função expressiva ou "poética” - de acordo com Jakobson (1974), o modo de expressar a mensagem e não seu conteúdo). Performance então aparece como uma "experiência humana contextualizada”, de cujos atos performáticos podem-se distinguir várias características, como: display (exibição dos atores), responsabilidade de demonstrar competência, avaliação dos participantes, experiência colocada em relevo, keying (sinais que focalizam o evento e indicam como ele deve ser interpretado). Nessa perspectiva, segundo Langdon, a performance é vista como uma atividade universal, daí a preocupação com a problemática da tradução e da fixação dos eventos de performance em textos escritos que contemplem tanto seu aspecto emergente quanto as negociações entre os participantes, a dialogicalidade e os poderes poéticos e retóricos aí envolvidos (Bauman; Briggs, 1990).

Langdon (1999) constrói um quadro comparativo entre o "modo clássico" de análise das narrativas e o "modo performático", onde questões como tradução, enfoque teórico, gênero de literatura, registro, voz, leitor, texto e narrador serão vislumbradas. Para ela, a preocupação com a textualização da literatura oral é um passo positivo, além de um elemento importante na tentativa de tradução cultural, especialmente em se considerando que estas abordagens mais contemporâneas dedicam-se a uma maior apreciação das qualidades estéticas e criativas da literatura oral. A autora ainda sublinha que, se a performance é uma experiência multissensorial, onde vários elementos contribuem para construir/representar a experiência em si mesma - e aqui entram fatores como movimentação corporal, o uso de diferentes sonoridades, e outros -, persistem na antropologia limitações no sentido de comunicar a totalidade dessas experiências.

Em relação aos estudos da performance, gostaria ainda de apresentar duas perspectivas de abordagem que, embora tenham tido origem no campo teatral, tanto sofreram influência como também influenciaram o campo antropológico, especialmente no que diz respeito às análises de narrativas orais, danças, rituais, representações teatrais e parateatrais, festas tradicionais e populares. Creio que, em meu trabalho, a consideração dessas duas perspectivas justifica-se porque, apesar da importante guinada teórica proporcionada por Bauman, por um lado, em direção à "arte verbal”, e das abordagens dramatúrgicas de Turner e Goffman, por outro lado, as manifestações corporais dos narradores - seu gestual, postura, posição e movimentação no tempo e 
no espaço - ainda não são suficientemente contempladas, e menos ainda sujeitas a análises específicas.

A linha de pesquisa chamada "etnocenologia" é uma das abordagens que pretende dar conta da análise dos eventos "espetaculares" como um todo. A etnocenologia surge, baseada numa crítica ao etnocentrismo do termo "teatro" (aplicável apenas a algumas culturas ocidentais), como um conceito alternativo que busca contemplar a universalidade das práticas espetaculares. Essa abordagem vem sendo desenvolvida há poucos anos, especialmente por Jean-Marie Pradier, na França, e tem como objetivo, segundo este autor, "o estudo, nas diferentes culturas, das práticas e dos comportamentos humanos espetaculares organizados” (Pradier, 1996, p. 16, tradução minha). Inspirado na obra de John Blacking, especialmente no tocante à argumentação deste na criação da disciplina de etnomusicologia, Pradier defende que a etnocenologia vem suprir uma lacuna nos estudos da relação entre corpo e produção simbólica. É aqui, então, que o termo "espetacular" ganha espaço, definido como "uma forma de ser, de se comportar, de se movimentar, de agir no espaço, de se emocionar, de falar, de cantar e de se enfeitar distinta do cotidiano” (Pradier, 1998, p. 24). Pradier, no entanto, admite a ambigüidade do termo e as falhas na sua definição, pois as pesquisas em etnocenologia acabarão se estendendo, buscando experiências e expressões espetaculares nas práticas, valores e símbolos também utilizados no cotidiano. ${ }^{8}$

Já o trabalho de Schechner (1988, 1992), localizado na confluência entre as pesquisas teatrais e antropológicas (o autor trabalhou em parceria com Victor Turner), faz uma interessante ligação entre ambas as perspectivas de análise. Para ele, a performance está enraizada na prática e é fundamentalmente interdisciplinar e intercultural (Schechner, 1988, p. xv). ${ }^{9}$ Considerando que os

8 No Brasil, Marocco (1996) vem desenvolvendo pesquisas nessa linha há mais de dez anos, buscando, na lida campeira dos peões (o laçar, o pealar, o domar, etc.) e na trova, uma análise do "gesto espetacular na cultura gaúcha”. É preciso que se perceba também que não apenas na cultura rural de fronteira, mas, acredito, em todas as culturas que não possuam um "teatro" organizado, nos termos ocidentais, a linha que separa as manifestações espetaculares organizadas das atividades cotidianas é, por vezes, bastante tênue.

9 Embora ambas as abordagens tenham em vista a relação entre performance e cultura, há, entretanto, uma diferença entre a escola norte-americana dos performances studies, desenvolvidos por Schechner, e a etnocenologia francesa de Pradier: enquanto esta focaliza o caráter êmico e individualizado das representações, aquela, ainda que também considere suas atribuições êmicas, volta-se, numa perspectiva intercultural, para estudos comparativos, vislumbrando universais do comportamento humano.

Horizontes Antropológicos, Porto Alegre, ano 11, n. 24, p. 125-153, jul./dez. 2005 
performances studies envolvem diversas artes, atividades e comportamentos, Schechner (1992, p. 273) organiza as atividades performativas da seguinte maneira: de acordo com a relativa "artificialidade” da atividade ou gênero, com a necessidade de treinamento formal, com o relacionamento entre "espaço teatral" e "evento teatral" e com o status social e ontológico de quem está atuando e de quem está sendo representado. Mas, segundo o próprio autor, sua taxonomia é falha, pois freqüentemente uma performance mistura ou exclui algumas destas categorias. A discussão vivaz sobre os estudos da performance, suscitada por Schechner ao longo dos últimos 20 anos, permite que se vislumbre em suas palavras a amplitude das questões envolvidas nessa perspectiva de abordagem da sociedade:

Performance is no longer easy to define or locate: the concept and structure has spread all over the place. It is ethnic and intercultural, historical and ahistorical, aesthetic and ritual, sociological and political. Performance is a mode of behavior, an approach to experience; it is play, sport, aesthetics, popular entertainments, experimental theatre, and more. But in order for this broad perspective to develop, performance must be written about with precision and in full detail. (Schechner, 1992, p. 4).

Para Schechner (1992), a performance é um conceito central no pensamento de Turner justamente porque os gêneros performativos seriam exemplos vivos do ritual em/como ação. Nesse sentido, conclui o autor, a performance, mesmo quando é abertamente ritualística - como numa cerimônia de cura, numa viagem xamânica ou no "teatro pobre” de Grotowski, terá sempre seu cerne de ação ritual, onde há um “comportamento restaurado”.

A forma spetaculaire (francesa), assim como a performance (norteamericana), adequa-se à minha proposta de abordagem dos narradores e narrativas orais da fronteira especialmente porque propõe a análise dos fenômenos expressivos como um todo, considerando a forma e o sentido dos eventos a partir dos elementos que o constituem - o performer, a audiência, as técnicas corporais, vocais e a interação de ambos, o uso de objetos, adereços e indumentárias, localização temporal e espacial, etc. -, contextualizados na cultura onde foram gerados.

A partir das definições de performance expostas acima, é importante não perder de vista o fato de que esta forma de expressão faz uso da linguagem poética, de que o corpo é o veículo que dá forma ao que se quer comunicar e 
de que todo ato de performance é reflexivo, cria uma experiência ao mesmo tempo em que reflete sobre ela. Quando trabalho com a noção de linguagem poética inspiro-me naquilo que Jakobson (1974) atribui à linguagem verbal, ampliando-o ao nível da linguagem corporal: na poética estão envolvidas seleções e combinações não usuais de elementos. Além disso, a função poética é a única dentre as funções da linguagem que trata da própria mensagem, ou seja, é auto-referenciada, logo, propicia reflexão sobre os próprios processos constitutivos da linguagem. ${ }^{10}$

A performance torna-se, portanto, não apenas mais um objeto de pesquisa, mas "o" objeto de pesquisa privilegiado para dar conta do universo multifacetado, fragmentado, processual e dialógico da cultura. Esse conceito, entretanto, como vimos, se salienta por possuir usos e conotações bastante diferenciadas. Em minha pesquisa, ${ }^{11}$ trabalho sob duas perspectivas: por um lado, da performance como desempenho, que pressupõe o envolvimento integral do contador no ato de narrar, seu desempenho vocal e corporal, ainda que a sua ênfase esteja no conteúdo, ou seja, no "evento narrado" (como ocorre nas narrativas pessoais); por outro lado, da performance como espetáculo, que envolve maior elaboração estética, lida com a linguagem poética, exige a presença de uma audiência caracterizada como tal, tem início e fim bem definidos, ou seja, prioriza o "evento narrativo" (é o caso de grande parte das performances dos causos/cuentos da fronteira).

Na seqüência do artigo serão analisadas duas performances narrativas, uma de caráter público, onde a idéia de "arte verbal” se encontra mais desenvolvida e os aspectos estéticos podem ser melhor analisados (noção de

\footnotetext{
${ }^{10}$ Outra função da linguagem observada por Jakobson (1974), especialmente útil em minha análise das performances narrativas, é a chamada "função fática", que evidencia o contato entre narrador e ouvinte (como quando o contador usa expressões como "né”, "viste?” ou faz algum comentário que chame a atenção do ouvinte para o fato narrado). Jakobson também avalia os usos das funções "conativa” (voltada para o destinatário), "metalingüística” (referencia os códigos lingüísticos utilizados), "referencial” (relativa ao contexto) e "emotiva" (relativa ao remetente) nos processos de linguagem. Estas, no entanto, não serão aqui utilizadas.

${ }^{11}$ Realizo pesquisa de campo na região da fronteira entre Argentina, Brasil e Uruguai desde 1998, numa faixa que avança em torno de $100 \mathrm{~km}$ nos limites políticos de cada um dos países. Embora os dois eventos narrativos incluídos neste artigo tenham ocorrido no lado brasileiro, podem ser considerados, dentro de minha perspectiva analítica, igualmente a eventos ocorridos nos outros países (que constam de minha tese de doutorado - Hartmann, 2004). Todos são, nessa perspectiva, "da fronteira".
} 
“performance como espetáculo”), e outra de caráter privado, onde - apesar de diluída num relato autobiográfico, cuja ênfase está no conteúdo (que também será analisado) - a poética característica da cultura da fronteira também pode ser observada (noção de "performance como desempenho").

\section{Performance como espetáculo: a narrativa de Seu Reni}

Nas narrativas orais contadas na fronteira, à exceção daquelas ocorridas em meio a grandes eventos (como um almoço, uma festa de aniversário ou uma peña folklórica), dificilmente se consegue determinar com exatidão um início e um fim. Isso porque, em geral, os causos ou cuentos tradicionais surgem em meio a relatos mais extensos, sobre a vida dos contadores, e muitos acabam sendo incorporados nos relatos de suas experiências particulares. A narrativa abordada nesse momento, entretanto, tem características de "performance como espetáculo", ou seja, além de possuir dispositivos bem marcados de início, meio e fim, foi pública, lida com a linguagem poética e envolve grande engajamento corporal e vocal do contador, que procura demonstrar "competência comunicativa" (Hymes, 1975).

A proposta de trabalho sobre essa performance visa, além de experimentar formas de textualização da forma oral para a escrita, realizar também uma análise que permita depreender dela o máximo de informações sobre as estratégias de oralidade dessa comunidade narrativa.

Na transcrição dessa narrativa busco uma diagramação que se aproxime do fluxo da emissão em sua forma oral. Para tanto, foram utilizados os seguintes dispositivos: mudanças de linha indicam separação de sentenças e são relativas a pequenas pausas de respiração feitas pelo contador; letras maiúsculas indicam pronúncias enfatizadas em volume mais alto; repetição de vogais indica sílabas alongadas; grafia incorreta de algumas palavras busca representar sua pronúncia na oralidade. Essa diagramação permite também que as diferentes estratégias utilizadas pelo contador, como o recurso à linguagem poética (rimas, repetições), à função fática (apelo à audiência), representação das falas dos personagens (reported speech), etc., transpareçam de forma mais evidente. Em relação à reported speech, devo explicitar que este é um dos principais dispositivos utilizados pelos contadores para conectarem os eventos narrados aos eventos narrativos (Bauman; Briggs, 1990, p. 70). Essa atualização do evento narrado, proporcionada pela fala em primeira pessoa, permite ao 
narrador expressar uma grande variedade de vozes, comportamentos e pontos de vista, oportunizando também uma demonstração de sua competência. ${ }^{12}$ De qualquer forma estas são apenas alternativas de análise e de “tradução” da oralidade para a escrita. ${ }^{13}$

Essa performance ocorreu numa tarde chuvosa, num gabinete da Câmara de Vereadores de Caçapava do Sul (RS), onde se encontravam o vereador Joãozinho, de 40 anos, seu assessor, Seu Clóvis, de 62 anos, Seu Reni, de 65 anos, Seu Valter, de 67 anos e eu. O vereador, nesse caso, era um reconhecido contador da cidade e em seu gabinete, pelo que pude observar, costumavam se formar verdadeiras “rodas de causos”. Naquele dia, os presentes disputavam a palavra para contarem histórias como esta:

Seu Reni Eu vou te contar só mais essa daqui:

tinha um senhor que tinha uma fazenda

que tinha um figueiral

mas todo mundo roubava figo dele. Pode gravar isso aí que eu vou me rir depois...

Tá gravando?

Eu

Seu Reni Cacique grava tudo.

Tá gravando. [enquadre de início (frame) - o contador assume a responsabilidade]

[linguagem poética $=$ repetição, paralelismo] [drama]

[função fática = interação com a audiência] [função fática] 
O cara...

O nome dele era João Silveira

e ele tinha um figueiral.

Ele rondava lá com uma arma,

[linguagem poética $=$ rima $]$

uma espingarda daquelas de

carregar pela boca

com duas buchas de pano, assim.

[performance corporal $=$ demonstração da ação narrada]

E quando iam roubar figo lá ele dava tiro pra TUdo quanto era lado.

Aí os caras descobriram que ele tinha medo de assombração.

Sabe o que é assombração?

Que existem nessas fazendas, nas casas mal-assombradas, né. Aí... cinco caras...

não, três caras, se combinaram: "Tchê, vamos roubar, cada um, um saco de figo desse homem."

[performance vocal = ênfase]

[função fática $=$ apelo à audiência]

Aí chegaram e...

sabiam que ele tava lá rondando, lá no início das figueiras.

Aí veio um agarrado no outro

aí fizeram aquelas...

veio um agarrado nas cadeiras do outro, assim, caminhando no meio do figueiral.

E aí quando viram, ele tava lá, [reflexão do narrador] [fala em primeira pessoa (reported speech)]

[performance corporal $=$ representação da ação narrada] aparecendo o cano da armazinha. E aí o da frente dizia assim: "No tempo que eu era viiiivo aqui era o caminho dos fiiigoo..."

[reported speech / linguagem poética $=$ rima, prolongamento das palavras]

E aí o véio decerto se ouriçou [linguagem poética $=$ metáfora: ouriçar-se (arrepiar-se como um ouriço)] 
lá no meio da árvore

e ficou lá, meio tremendo.

E aí eles:

"E eu que sou mooorto

vou agarrar o dos oooutrooos..."

[reported speech /

linguagem poética $=$ rima,

prolongamento das

palavras]

E aí a coisa foi chegando perto.

$\mathrm{E}$ aí quando chegaram por aqui,

[linguagem poética $=$ repetição]

como por essa porta assim, disseram:

"E eu que sou alma traseira

vou pegar João Silveira

que tá atrás da figueeira!"

[reported speech I

linguagem poética = rima,

prolongamento das

palavras]

E ele ó,

[performance corporal $=$ gesto com as mãos representa a fuga]

SAIU correndo.

[performance vocal $=$ ênfase]

Diz que até ontem de tarde eles ainda tavam apanhando figo... [risos]

[enquadre de fim / "diz que" busca a legitimidade do evento narrado / "até ontem de tarde" atualiza o evento]

O que há por trás das evidências, das questões aqui apontadas? Em primeiro lugar, verifica-se uma certa moral que emerge dessa performance narrativa. Numa tentativa de interpretação, pode-se aferir que, para esses gaúchos, um homem que não compartilha seus bens acaba perdendo-os. O roubo, assim,

${ }^{14}$ Temos aqui uma demonstração da capacidade da performance, apontada por Zumthor (2000, p. 36), de provocar o reconhecimento de algo até então virtual em real, atual. Tedlock (1983) também aponta esta convergência de temporalidades e espacialidades nas narrativas orais, daí o seu caráter de "atualidade". 
aparece aqui como perfeitamente legítimo. Poderia ainda arriscar: a coragem que não se sustenta frente à uma "assombração", é apenas covardia de arma na mão. É a vitória da esperteza sobre as normas sociais que privilegiam poucos (poderíamos ir mais longe se pensarmos como o próprio conceito de "propriedade privada" é tratado de forma ambígua na região). Uma performance como essa também traz a possibilidade de brincar, jogar, não apenas com as regras sociais, mas com as palavras, com os significados, com o próprio corpo e com o contato com o outro, proporcionando, além da transmissão de códigos de comportamentos culturais, entretenimento e prazer a todos os seus participantes.

É interessante ainda refletir a partir desse "causo", apoiada na perspectiva de Hymes (1975), o que dele emerge como "maneira de falar" (ways of speaking) - e, eu acrescentaria, maneira de agir (performatizar) dessa comunidade narrativa. Assim, em primeiro lugar, percebe-se uma pretensão de gerar riso e divertimento à audiência, sendo que o riso vem justamente pelo contraste entre a brincadeira e um tema sério (no caso, um roubo). Esse contraste é evidenciado mais fortemente através da performance corporal, como a representação dos homens agarrados uns à cintura dos outros.

Em relação à performance, o contador assume a responsabilidade pela narração, anunciando esta com um enquadre (frame) que indica o início da história. Ele também realiza pequenas dramatizações (tanto corporais quanto vocais - reported speech), onde são representados comportamentos de seus personagens, ou seja, abandona momentaneamente o uso da terceira pessoa e, deixando de narrar, passa a atuar, representando, em primeira pessoa, os papéis de seus personagens. Esse aspecto permite lembrar a argumentação de Mato (1990) em defesa da classificação das narrativas orais no âmbito das formas dramáticas, cênicas, daí a terminologia por ele usada para definir esse tipo de expressão: "arte de narrar".

Finalmente, Seu Valter trata de temas relativos à própria sociedade de maneira irônica, instigando a audiência, através desse recurso, à reflexão e à crítica.

\section{Performance como desempenho: a história de vida de Gaúcho Barreto}

Meu intuito aqui é trabalhar a noção de "performance como desempenho” a partir da transcrição e análise de um fragmento da história de vida de 
um narrador da fronteira. Ao invés de uma história com começo, meio e fim, pretendo agora apontar a fluência cotidiana de um relato que encadeia narrativas diversas, sem precisar-lhes um término. Nesse sentido, acompanho a perspectiva de Kirshenblatt-Gimblett (1975) de que os contos de tradição oral não são peças autônomas. A autora critica a desconsideração, por parte dos pesquisadores, pelos atos de fala - outros contos ou formas não narrativas - que precedem os contos. Estes, segundo ela, criam enquadres (frames) de referência para as histórias que serão contadas. Ela também argumenta que o "contexto da situação" - informações do ambiente, da audiência, etc. - ajuda a compreender como o evento narrativo é estruturado e como um contador criativo integra uma história tradicional ou de domínio público num contexto de interação social específico. Dessa forma, apresento inicialmente o narrador em questão, situando-o em relação ao seu contexto. Na seqüência, transcrevo literalmente nossa conversa e finalmente analiso seu desempenho/performance durante a narração. Assim, embora procure recuperar a relação entre as experiências de vida desse contador e as histórias por ele contadas, ${ }^{15}$ isso será feito no âmbito do evento narrativo (a performance do contador e suas estratégias de oralidade), em detrimento dos eventos narrados (o conteúdo abordado). Como possui características diferentes da performance analisada anteriormente, a menção aos elementos que a compõe não será feita ao lado, mas no final da narrativa.

Barreto é um contador de causos conhecido, sobretudo no lado brasileiro da fronteira, por seu estilo loquaz, seu jeito bonachão, seu humor mordaz e seus poucos pudores para contar aquelas histórias das quais nem sempre a comunidade se orgulha. $\mathrm{O}$ formato de apresentação de sua história de vida obedece ao seqüenciamento estabelecido por ele no momento da performance.

Tive de realizar um difícil trabalho de edição a fim de possibilitar a análise aqui proposta e, ao mesmo tempo, não fatigar o leitor. Esses cortes serão indi-

\footnotetext{
${ }^{15}$ Em seu belo trabalho, realizado juntamente com três narradoras indígenas norte-americanas, Cruikshank (1998) parte da premissa de que as histórias de vida oralmente narradas são uma estratégia para representar a experiência cultural. Para ela, as autobiografias também são modeladas por convenções narrativas. Ela considera que as narradoras usam as dimensões tradicionais da cultura como um recurso para falar do passado, o que pode aportar contribuições para a compreensão de processos culturais por elas vividos. Segundo a autora, para interpretar uma história de vida narrada oralmente é necessário que o/a pesquisador/a conheça suficientemente o background do/da narrador/narradora, construindo o contexto para ouvir - e compreender - o que é dito.
}

Horizontes Antropológicos, Porto Alegre, ano 11, n. 24, p. 125-153, jul./dez. 2005 
cados no texto por reticências entre parênteses [...]. Os demais dispositivos gráficos são os mesmos utilizados na transcrição anterior. Optei por manter os comentários e questões feitas por mim durante a interação com Barreto, pois acredito que estes são também parte integrante do contexto e, como tal, importantes para a compreensão do evento narrativo como um todo.

Barreto é meu velho conhecido. Fomos apresentados quando eu visitava um acampamento de tradicionalistas que levavam a "Chama Crioula" de Alegrete para Santana do Livramento (RS). Ele estava com um grupo de gaúchos, alguns já um pouco borrachos (embriagados), “churrasqueando” e contando "causos” num pequeno galpãozinho da estância que os acolhia por aquela noite. Depois disso, nos encontramos em diversas outras ocasiões. Além de exímio contador, Barreto tem um bolicho (bar/armazém) onde se encontram peões e gente da campanha em geral, que têm ali, nas ocasiões que vêm à cidade, um local para beber ou comer algo e também para procurar trabalho, pois é comum os estancieiros da região deixarem lá anúncios informais de emprego.

A conversa transcrita a seguir ocorreu na cozinha/refeitório que fica nos fundos do seu bolicho, em Santana do Livramento, numa tarde morna de novembro.

Eu - Só pra começar então eu queria que tu me dissesses...

Barreto - Tu me pergunta. Tu que me pergunta.

$\mathrm{Eu}$ - Tá, queria que tu me dissesses teu nome completo...

B - Antônio Carlos Guedes Barreto, Alegrete, 23 de fevereiro de 1940, Lajeado Grande. Nascido em campanha por uma parteira, Maria Isabel. Uma negra mina foi quem me cortou o imbigo. É minha madrinha. Preta como o meu passado.

Antigamente na campanha as... as senhoras ganhavam os filhos longe, não tinha maternidade, era com as parteiras que existiam, era parteira de campanha. Como a vó Chininha aqui, a vó Chininha foi parteira de campanha. Ela tá com quase cem anos, tu tem que falar com ela. [...]

A minha família foi o seguinte: eu nasci de um homem pobre como eu. O meu pai foi vendedor de bilhete em Santana do Livramento, foi bilheteiro, tempo dos bilhete de sorte grande... foi lustrador de sapato... Depois de uma certa idade, semi-analfabeto, era muitos filhos que o meu avô tinha - ele era meio perverso, o meu avô era subdelegado - o meu pai foi embora pra... Cacequi, onde tinha um irmão. Que naquela época ganhava-se dinheiro com o contrabando de seda, era muito falado a seda, a seda do Uruguai. E o meu tio esse tinha uma tropilha de mulas, carregava em carga de mula, e o meu pai foi trabalhar com ele. [...]

Foi passando-se os anos e o meu pai já tinha dezenove anos de idade quando

Horizontes Antropológicos, Porto Alegre, ano 11, n. 24, p. 125-153, jul./dez. 2005 
conheceu a minha mãe, com vinte e nove, dez anos mais velha que ele. O meu pai era um homem... como é que eu vou te dizer... rústico, grosso, mas porém... tipo muito conquistador, muito dançador era, dançava muito bem o meu pai, era um homem com bastante presença. Homem novo, grosso, mas de boa presença, gostava de se arrumar bem arrumado. Achou aquela velha naquele fundo de campo lá no Alegrete... [... . Aí conheceu a mamãe... e por aí seguiu o namoro. E o meu avô não queria de jeito nenhum. Ele inclusive pagava um negro - naquela época sempre eles tinham um negro, naquela época diziam “um negro”, a pé - pra avisar o meu pai que não queria, que senão ele ia se dar mal, que se ele tentasse de fazer qualquer coisa que desse causo de amor com a minha mãe, o negro ia matar ele. O negro era... como é que eu vou te dizer... ele era um capanga do meu avô, o meu avô era fazendeiro muito forte naquele tempo. Mas não houve de capanga nem nada, o Seu Cório Barreto, muito bonitão, muito dançador de tango, foi levando, foi levando e levou o velho... Aí o meu pai casou e ficou lá... e tiveram que dar um pedaço de terra pra ele. [...]

E ele viveu lá com a minha mãe, se casaram, foram viver lá naquele fundo de campo, mas em seguida, ele muito mais nooovo, ela mais veeelha, e teve filho... e tu vê que a mulher ficou muito mais velha que o homem. E ele não sabia nada de campanha, nada, nada, nada, nada! Ela que ensinou tudo a ele, andar de cavalo... ele mal e porcamente encilhava um burro e não andava a cavalo. Ela que conhecia o gado e... E aí foi indo, mas não durou muito tempo o meu pai começou a ficar malandro. [...]

Aí nós fiquemo pequeno quando ele deixou da minha mãe. Eu tinha... quando ele deixou da minha mãe eu tinha uns doze... 13 pra 14 anos. Foi quando eu me alcei pro mundo. Eu via aquela briga em casa, bateção de boca, eu já peguei e disse prá mãe: "Olha, eu vou-me embora pra não fazer um atrito com meu pai, que passa batendo boca e deixa e deixa e não se deixa... e as minhas irmãs pequenas tão precisando, eu vou procurar um trabalho." "Mas guri...”, "Não, eu não agüento mais ele, tá me judiando muito, e eu vejo ele judiar de ti, então vou me embora.” [...]

E eu fugi de casa, não pedi... só um zaino [cavalo], uma muda de roupa e fui pra primeira fazenda, do finado Mário Paiva. Cheguei lá fugido. Quando... na cruzada do marco Lopes, naquela época tinha uns postos... dos brigadiano, nós dizia “os rural”. Era o Jaime, era bem preto, e me prendeu. Eu vinha com aquele petiço [cavalo] véio manco já, ele viu aquele piá de a pé, puxando um petiço... com uns pedaço de carne, de chapéu de lona, ele viu que eu não era... "De onde é que tu é? Tá preso!” Muito bem, fiquei dois dias no posto. Ele me dizia: “Se tu fugir daqui eu te mato. Pra onde é que tu vai?” Aí contei a história real pra ele: “Não, eu fugi de casa por isto e por isto e por isto. Eu sou filho do fulano.” Aí ele me largou [...] Eu queria ir pra uma estância grande onde eu pudesse aprender a trabalhar e 
ganhar pra ajudar a mãe. Eu fui com 13 pra 14, saí com 19 pra servir, tirei três anos no quartel, voltei, tirei mais cinco anos na fazenda. Eu era muito bem quisto na fazenda, sempre fui muito espontâneo, muito trabalhador, gostei de trabalhar, de não incomodar ninguém... nunca pendi pra esse lado da cachaça, de beber, nunca fui... sempre gostei de baile quando novo, mas nunca fui de alaúza [baderna]. De primeiro demorava três, quatro, cinco meses sem vir na cidade e quando vinha, vinha com o dinheiro justo pra ajudar a minha mãe. [...]

$\mathrm{Eu}-\mathrm{E}$ esse bolicho que tu tiveste na linha [de fronteira]: tu tinhas o teu bolicho e junto tu tinhas o teu caminhãozinho pra fazer os contrabandos?

B - Não, não, não tinha caminhão nessa época. O bolicho, eu vou te contar bem certo já que tu quer saber como é que é: eu fui pra ali pra... sabia o que dava de contrabando. Eu morei dez ano ali. Aí eu disse pro finado Barbeiro: “Tchê, tá dando pra importação de gado. Vamos sondar pra ver o que dá prá nós fazer, né.” Dito e feito, fomos pra lá. [...] Aquilo era uma fachadinha de boteco, mas no fundo do botequinho eu tinha um fusquinha amarelo, nós vinha aqui, entrava pro lado do Uruguai e trazia por trás, carregado... porque fusca é como burro, cruza em qualquer lado... Trazia de lá 30, 40 pacotes de cigarro, dois, três videocassetes, 15, 20 litros de uísque. [...] Depois foi ficando ruim, aí não deu mais. Bolichinho... verdadeiro. Duas porta, uma em frente à outra, uma no Brasil e outra no Uruguai, a casa beeem na beira da linha, beeem no límite [demonstra], bastante espaço... [...]

$\mathrm{Eu}$ - Barreto, e os peões quando queriam namorar ou ver as esposas tinham que ir pra cidade?

B - É, sempre se visitavam quando era perto. Perto modo de dizer, né, cinco, seis horas de a cavalo, troteando pra chegar. Bailão, carreirada... Já tinha um gaiteiro ali pela volta, toca uma música, toca outra... E toma uma cerveja, já dá uma olhada pra filha do capataz, ela já dá uma olhadita, faz senha se dá ou não, dá uma volta, já sai pelo meio de uma arvorezinha ou vai por uma outra sombra, e tu vai chegando devagarinho. E se dá uma milongueada, dá, se não dá, boa-noite. Mas nunca o gaúcho dá incerta. De quebrar o prato é difícil. Ah, não, o gaúcho não dá. Se gostava da guria... tirava pra dançar... já perguntava: “tu me quer e eu te quero, nós semo dois quero-quero, né... Que que tu achou do meu jeito, gauchita? Sou um homem meio solteirão, meio gauchão, ando atrás de uma prenda.” Já dizia alguma que... usava falas: que tu é bonita, tu é linda, que o teu sorriso, que o teu olhar... "Esta morena tem um caminhar descontraído”, dizia o finado Canabarro, coitado. Quando cruzava uma morena bonita ele dizia assim pra mim: “Tchê, Barreto, esta morena tem um olhar de mormaço e um caminhar descontraído.” Piada de campanha (risos). E aqueles homens se atropelavam: "Vamos dançar?” E o mais esperto ficava meio de longe, vendo se dava ou não... Se ela fazia um jeito com o cabelo assim [demonstra], já sabia que dava, que ela queria dançar contigo. Daqui 
a pouco, quando os pais saíam, ela vinha, aí é que tu ia ver se ela tava com o olhar de mormaço e o caminhar descontraído! (risos) Essa Luciana vai levar coisa pra contar dessas fronteiras! ${ }^{16}$

O contexto do evento do qual extraí as narrativas transcritas acima, como já comentei, era de uma conversa informal, nos fundos do bolicho de Barreto. Éramos apenas nós dois no ambiente, sentados em torno da mesa e tomando mate. Apesar dessa situação em princípio pouco favorável para a execução de uma grande performance (especialmente devido à pequena audiência), Barreto demonstrou ser o hábil narrador cuja fama percorre a fronteira.

Enquanto fala, Barreto gesticula bastante, embora naquela ocasião quase não tenha se levantado. Ele também utiliza diversas variações vocais, o que confere grande vivacidade às suas narrativas e estimula a atenção da audiência. Essas variações incluem muitas vezes a representação, em primeira pessoa, das falas de seus personagens (reported speech), um recurso, como vimos, de aproximação entre o evento narrado e o evento narrativo que permite que personagem e audiência encontrem-se no presente. Esses personagens representados por Barreto tanto podem ser ele próprio em outro período de sua vida (“Olha, eu vou-me embora pra não fazer um atrito com meu pai...”) quanto um brigadiano (“De onde é que tu é? Tá preso!”) entre outros.

Com a audiência (no caso eu - a pesquisadora), Barreto desenvolveu uma forte interação, o que revela o prazer que tem ao contar e também a influência que um ouvinte atento pode exercer tanto na execução da performance quanto no conteúdo do que é narrado. Já no começo de nossa conversa Barreto interrompe minha primeira questão dizendo: "Tu me pergunta. Tu que me pergunta.” Ao recorrer à função fática, o contador me deixa confortável para questionar-lhe.

Em diversos outros momentos Barreto dirige-se a mim para indicar uma contadora: “tu tem que falar com ela” (referindo-se à vó Chininha). Com isso, além de afirmar a rede de contadores, o contador indiretamente se exime da responsabilidade, afinal, vó Chininha tem quase cem anos, o que lhe confere

\footnotetext{
${ }^{16}$ Apesar de extenso como citação, o que mantive nesse fragmento da longa conversa que tive com Barreto foi o mínimo necessário, creio, para propiciar ao leitor a compreensão do encadeamento de narrativas, entremeado de perguntas e comentários, que caracterizam a dinâmica de um evento desse gênero.
}

Horizontes Antropológicos, Porto Alegre, ano 11, n. 24, p. 125-153, jul./dez. 2005 
uma legitimidade muito maior que a dele para contar. Esta é uma estratégia muito utilizada pelos contadores da fronteira, que num primeiro momento negam a responsabilidade - disclaimer (Bauman, 1977) - pelo que estão contando, ou transferem-na para outro contador, e num momento seguinte assumem esse papel.

Quando anuncia: “A minha família foi o seguinte:...”, Barreto está enquadrando as narrativas que contará, ou seja, está fornecendo dispositivos (frames) para que audiência possa se preparar para o que vai escutar. Dessa forma, ao enunciado seguir-se-á uma narrativa pessoal.

O uso que faz da linguagem poética, através do uso de metáforas, por exemplo ("preta como o meu passado"; "me alcei pro mundo"), e a forma elaborada com que escolhe as palavras ("eu nasci de um homem pobre como eu”), além demonstrar o domínio que o contador tem dessa linguagem, também permitem pensar que ele possui um longo exercício no papel e que possivelmente já narrou mais de uma vez essas suas histórias pessoais e causos. As metáforas, escolhidas sem dúvida dentro de um repertório local, são também expressões simbólicas do ethos desse gaúcho representado por Barreto: seu passado "preto" = no caso, errado; "alçar-se" = refere-se ao gado vacum ou à pessoa que tem uma atitude de desobediência ou uma resolução inesperada e foge para os matos ou para os banhados e torna-se bravio, torna-se selvagem (Nunes; Nunes, 2000, p. 26). Não por acaso uma das metáforas aqui analisadas remetem ao universo rural, principal referência, como aponto em minha tese (Hartmann, 2004), para o imaginário da e sobre a fronteira. ${ }^{17}$

Além das metáforas, Barreto também recorre a outros dispositivos da linguagem poética, como as repetições (“não sabia nada, nada, nada...”, referindo-se ao pai; as palavras alongadas, recurso fartamente utilizado pelos conta-

\footnotetext{
${ }^{17}$ De acordo com Lakoff; Johnson (1980), as metáforas não são um dispositivo exclusivo da imaginação poética, mas participam da vida cotidiana. As metáforas, segundo eles, fazem parte tanto da linguagem quanto do pensamento e da ação - "nosso sistema conceitual é fundamentalmente metafórico” (Lakoff; Johnson , 1980, p. 3, tradução minha). E já que a comunicação está baseada no mesmo sistema conceitual que usamos para pensar e para agir, a linguagem funciona como um importante recurso para evidenciar/dar forma a esse sistema. Dessa forma, segundo os autores, uma cultura que desenvolva sua base conceitual em termos de "guerra”, utilizará metáforas nesse sentido. No nosso caso, é possível constatar que a comunidade narrativa de fronteira, que tem na ruralidade um de seus mais fortes referenciais, adota em sua linguagem, cotidiana e extracotidiana, metáforas que remetem a esse referencial.
}

Horizontes Antropológicos, Porto Alegre, ano 11, n. 24, p. 125-153, jul./dez. 2005 
dores da região (“ele muito mais nooovo, ela muito mais veeelha”). A recorrência a provérbios locais durante os relatos, conversas ou narrativas ("Fusca é como burro, cruza em qualquer lado") também demonstra a familiaridade da população com essa forma de linguagem. Quando conta dos bailes que freqüentava, Barreto também recorre diversas vezes à linguagem poética, possivelmente inspirado pelas situações mencionadas: "Tirava pra dançar... já perguntava: 'tu me quer e eu te quero, nós semo dois quero-quero...”, ou ainda: “esta morena tem um olhar de mormaço e um caminhar descontraído.”

A utilização da linguagem poética, como se percebe, não pertence exclusivamente ao domínio das “performances como espetáculo”, ao contrário, está presente na vida cotidiana dessa comunidade, o que permite que seja manipulada em situações de intimidade, como nos eventos onde são contadas as narrativas pessoais. Ou seja, essa "poética" participa das expressões orais da fronteira em seus diversos níveis.

Outro aspecto que emerge das narrativas de Barreto, de grande importância para a compreensão das tradições orais da fronteira, é o uso combinado dos idiomas - no caso português e espanhol, identificando sua comunidade narrativa com a "comunidade de fala" da fronteira. Barreto é brasileiro, mas sua experiência "na linha”, pelas relações de amizade, comércio (contrabando) ou lazer, gera uma maneira de expressar-se própria da fronteira. Assim, ele utiliza com frequiência a palavra cuento como sinônimo de causo, comissão de límite para referir-se ao setor do governo que coordena a cessão de terras fronteiriças, etc.

O fato de Barreto ser um viajante - no caso, contrabandista - confirma uma das principais características dos contadores da fronteira: o trânsito através dos países vizinhos. Responsáveis pela circulação das narrativas orais através da região, os viajantes - tropeiros, domadores, esquiladores, contrabandistas, parteiras... -, ao contarem suas histórias, criam uma comunidade que traça, através das narrativas, novos limites para sua fronteira, não mais política, mas simbólica.

A questão da reflexividade provocada pelas narrativas também pode ser depreendida da fala de Barreto. Por exemplo, depois de mencionar a fala do amigo ("essa morena tem um olhar de mormaço..."), Barreto reflete sobre o próprio fato contado: "Piada de campanha.” Em relação a esse comentário, é interessante ressaltar ainda que a campanha, ou o meio rural, aparece novamente como o enquadre de referência, que permite contextualizar o evento narrado e assim compreender seu significado. 
No final de nossa conversa o contador demonstra a percepção que tem de minha presença ali e da importância de sua atuação para a realização de meu trabalho: "Essa Luciana vai levar coisa pra contar dessas fronteiras!"

Em relação à performance corporal do contador, como foi dito inicialmente, esta se caracteriza não pelo deslocamento no espaço, mas pela hábil manipulação dos tempos narrativos, intercalando silêncios a fortes expressões vocais. Sua postura, mesmo sentado, compartilha códigos do comportamento masculino da fronteira: ${ }^{18}$ coluna levemente curvada para a frente, pernas afastadas, com uma das mãos (normalmente a direita) apoiadas na parte interna da coxa, formando um ângulo de quase 90 graus com o antebraço e o antebraço oposto apoiado na coxa da outra perna.

Outra característica de Barreto, semelhante a outros contadores da fronteira, é a representação de ações específicas de seus personagens ou de si próprio através do gestual. Dessa forma, no final de seu relato, quando fala das estratégias de sedução utilizadas por gaúchos e gaúchas nos bailes, ele representa - comicamente - a ação que as moças faziam com o cabelo para indicar se estavam ou não interessadas no rapaz.

Pensando, na perspectiva de Hymes (1975, p. 70), de que a tradição é feita por pessoas, é possível considerar que, na performance analisada acima, alguns aspectos que sobressaem, como o fato do contador assumir a responsabilidade pelo que está contando, ainda que em determinados momentos repasse a autoria da história a terceiros. Também é importante observar que os causos/ cuentos propriamente ditos aparecem sempre integrando narrativas mais longas, numa seqüência para a qual o contador estabelece uma lógica própria. ${ }^{19}$ Analiticamente, como vimos, é possível delimitar os cuentos/causos porque estes vêm enquadrados por dispositivos (frames) da performance tanto corporal quanto verbal.

A importância de conhecer, registrar e analisar o contexto da narração e também da narrativa está relacionada à questão do significado: este passa a ser

${ }^{18}$ É importante salientar que esse comportamento, entretanto, não ocorre exclusivamente na fronteira.

${ }^{19}$ Essa lógica particular deve ser considerada quando, por exemplo, um mesmo narrador agrega à sua trajetória de vida diferentes histórias, contando-a de diferentes maneiras em situações distintas. A legitimação desse processo, que pode ser chamado de “memória criativa” dos contadores, é abordada por Bauman (1988).

Horizontes Antropológicos, Porto Alegre, ano 11, n. 24, p. 125-153, jul./dez. 2005 
buscado não mais na própria história, mas no encadeamento particular das várias histórias, e é relativo a um contexto específico de interação com a audiência. Nesse sentido, a própria interpretação da audiência é estimulada pelo contexto (Kirshenblatt-Gimblett, 1975, p. 130). Finalmente, o contador, demonstrando especial disposição, entusiasmo e, por que não dizer, generosidade ao narrar, está refletindo sobre sua própria experiência - que, afinal, é também a experiência de viver numa fronteira, com sua cultura, seu imaginário e suas histórias.

Procurei demonstrar ao longo deste artigo que a prática de contar e ouvir histórias na fronteira está inserida em complexos eventos de fala que representam a vitalidade de uma tradição que é recriada dia após dia. Caracterizando uma importante parte do que denominei de "cultura da fronteira", as performances narrativas vão se constituindo com base em alguns fatores comuns, que procurei detectar e compreender. Um dos aspectos que se mostrou primordial para a análise dessas performances foi a observação do desempenho verbal e corporal dos contadores. Em relação ao desempenho verbal, como vimos, os contadores fazem uso da linguagem poética através de dispositivos como repetições, rimas, ênfases e o prolongamento de algumas palavras especialmente relevantes para o contexto de enunciação. Também recorrem com freqüência à função fática, através da qual estimulam o envolvimento da audiência no evento narrativo. Outra estratégia verbal - mas também corporal dos contadores da fronteira é a representação de seus personagens em primeira pessoa (reported speech). Embora em minhas análises eu tenha enfatizado apenas sua importância enquanto uma estratégia da fala, esta, sem dúvida, pressupõe o envolvimento integral do narrador.

É importante ainda ressaltar que a medida de utilização desses recursos é dada, em grande parte, pelo contexto de narração. Dessa forma, conforme o narrador se sinta desafiado ou estimulado pela audiência, mais ele fará uso desses recursos. Isso significa que tanto nas performances públicas quando nas performances privadas, relativas a narrativas pessoais/histórias de vida, os recursos podem ser disponibilizados em maior ou menor grau pelo narrador, pois fazem igualmente parte de seu repertório - ainda que inconsciente - de atuação. 


\section{Referências}

BAUMAN, Richard. Verbal Art as performance. Rowley, Mass.: Newbury House Publishers, 1977.

BAUMAN, Richard. Story, performance and event: contextual studies of oral narrative. Cambridge: Cambridge University Press, 1986.

BAUMAN, Richard. Ed Bell, Texas storyteller: the framing and reframing of life experience. In: HOFER, Tamás; NIEDERMÜLLER, Péter (Ed.). Life History as cultural construction/performance. Budapest: The Ethnographic Institute of the Hungarian Academy of Sciences, 1988. p. 247-280.

BAUMAN, Richard; BRIGGS, Charles. Poetics and performance as critical perspectives on language and social life. Annual Review of Anthropology, Palo Alto, v. 19, p. 58-88,1990.

BAUMAN, Richard; SHERZER, Joel. The Ethnography of speaking. Annual Reviews of Anthropology, Palo Alto, v. 4, p. 95-119, 1975.

BRIGGS, Charles. The pragmatics of proverb performances in New Mexican Spanish. American Anthropologist, Washington, DC, v. 87, n. 4, p. 793-810, 1985.

BRUNER, Edward. Ethnography as narrative. In: TURNER, V.; BRUNER, E. (Org.). The Anthropology of Experience. Urbana: University of Illinois Press, 1986. p. 139-155.

CRUIKSHANK, Julie. The social life of stories: narrative and knowledge in the Yukon Territory. University of Nebraska Press, 1998.

GEERTZ, Clifford. Making Experience, Authoring Selves. In: TURNER, V.; BRUNER, E. (Org.). The Anthropology of Experience. Urbana: University of Illinois Press, 1986. p. 373-380.

GEERTZ, Clifford. A interpretação das culturas. Rio de Janeiro: Guanabara Koogan, 1989.

GEERTZ, Clifford. "Do ponto de vista dos nativos”: a natureza do entendimento antropológico. In: GEERTZ, Clifford. O saber local: novos ensaios em antropologia interpretativa. Tradução de Vera Mello Joscelyne. Petrópolis: Vozes, 1997. p. 85-107.

GOFFMAN, E. The interaction order. American Sociological Review, v. 48, p. 1-17, 1983. 
HARTMANN, Luciana. Identidade, ambigüidade, conflito: as performances narrativas como estratégia de análise da cultura da fronteira entre Brasil, Argentina e Uruguai. Revista de Investigaciones Folclóricas, Buenos Aires, v. 17, p. 114-122, dic. 2002.

HARTMANN, Luciana. "Aqui nessa fronteira onde tu vê beira de linha tu vai ver cuento": tradições orais na fronteira entre Argentina, Brasil e Uruguai. Tese (Doutorado em Antropologia Social)-PPGAS/UFSC, Florianópolis, 2004.

HYMES, Dell. Breakthrough into performance. In: BEN-AMOS, Dan; GOLDSTEIN, Kenneth S. (Org.). Folklore - performance and communication. Paris: Mouton, 1975. p. 11-74.

JAKOBSON, Roman. Lingüística e poética. In: JAKOBSON, Roman. Lingüística e comunicação. Tradução de Izidoro Bilkstein e José Paulo Paes. São Paulo: Cultrix, 1974. p. 118-163.

KAPCHAN, Deborah A. Common ground: keywords for the study of expressive culture - performance. Journal of American Folklore, v. 108, n. 430, p. 479507, 1995.

KAPFERER, Bruce. Performance and the structuring of meaning and experience. In: TURNER, V.; BRUNER, E. (Org.). The Anthropology of Experience. Urbana: University of Illinois Press, 1986. p. 188-203.

KIRSHENBLATT-GIMBLETT. A parable in context: a social interactional analysis of storytelling performances. In: BEN-AMOS, Dan; GOLDSTEIN, Kenneth S. (Org.). Folklore - performance and communication. Paris: Mouton, 1975. p. 105-130.

LAKOFF, George; JOHSON, Mark. Metaphors we live by. Chicago: The University of Chicago Press, 1980.

LANGDON, E. Jean. A fixação da narrativa: do mito para a poética da literatura oral. Horizontes Antropológicos, Porto Alegre: PPGAS/UFRGS, ano 5, n. 12, p. 13-36, dez. 1999.

LÉVI-STRAUSS, Claude. Antropologia estrutural. Trad. Chaim Samuel Katz e Edinardo Pires. Rio de Janeiro: Tempo Brasileiro, 1967.

MALUF, Sônia. Antropologia, narrativas e a busca de sentido. Horizontes Antropológicos, Porto Alegre: PPGAS/UFRGS, ano 5, n. 12, p. 69-82, dez. 1999. 
MAROCCO, Inês Alcaraz. Le geste spetaculaire dans la culture "gaucha" du Rio Grande do Sul - Brésil. Tese (Doutorado em Estética, Ciências e Tecnologia das Artes)-Université de Paris VIII, Saint-Denis - Vincennes, 1996.

MATO, Daniel. Cuenteros afrovenezuelanos en acción. Oralidad: lenguas, identidad y memoria de América, La Habana, n. 2, p. 41-47, 1990.

NUNES, Zeno Cardoso; NUNES, Rui Cardoso. Dicionário de regionalismo do Rio Grande do Sul. 9. ed. Porto Alegre: Martins Livreiro, 2000.

PRADIER, Jean-Marie (Org.). Ethnoscénologie: la profondeur des émergences. Internationale de l'Imaginaire: nouvelle série, Paris: Babel/Maison des Cultures du Monde, n. 5, p. 13-41, 1996.

PRADIER, Jean-Marie. Etnocenologia. In: GREINER, Christine; BIÃO, Armindo (Org.). Etnocenologia: textos selecionados. São Paulo: Annablume: GIPE-CIT, 1998. p. 23-29.

ROSALDO, Renato. Ilongot hunting as story and experience. In: TURNER, V.; BRUNER, E. (Org.). The Anthropology of Experience. Urbana: University of Illinois Press, 1986. p. 97-138.

SCHECHNER, Richard. Performance theory. New York: Routledge, 1988.

SCHECHNER, Richard. Victor Turner's last adventure. In: TURNER, Victor. The Anthropology of Performance. $2^{\text {nd }}$ ed. New York: PAJ Publications, 1992. p. 7-20.

SCHIEFFELIN, Edward L. On failure and performance: throwing the medium out of the seance. In: LEADERMAN, Carol; ROSEMAN, Marina (Ed.). The performance of healing. London: Routledge, 1996. p. 58-89.

SCHIEFFELIN, Edward L. Problematizing performance. In: HUGHESFREELAND, Felicia (Ed.). Ritual, performance, media. London: Routledge, 1998. p. 194-207.

SINGER, Milton. When a great tradition modernizes. Chicago: University of Chicago Press, 1972.

SULLIVAN, Lawrence E. Sound and senses: toward a hermeneutics of performance. History of Religions, v. 26, n. 1, p. 1-33, 1986.

TEDLOCK, Dennis. Ethnography as interaction: the storyteller, the audience, the fieldworker, and the machine. In: TEDLOCK, Dennis. The spoken word and the work of interpretation. Philadelphia: University of Pennsylvania Press, 1983. p. 285-301. 
TEDLOCK, Dennis. From Voice and ear to hand and eye. Journal of American Folklore, n. 103, p. 133-156, 1990.

TURNER, Victor. Social dramas and stories about them. In: MITCHELL, W. J. T. (Org.). On narrative. Chicago: University of Chicago Press, 1981. p. 137-164.

TURNER, Victor. The Anthropology of Performance. $2^{\text {nd }}$ ed. New York: PAJ Publications, 1992.

ZUMTHOR, Paul. Performance, recepção, leitura. Tradução de Jerusa Pires Ferreira e Suely Fenerich. São Paulo: Educ, 2000.

Recebido em 31/05/2005

Aprovado em 04/07/2005 